\title{
Underweight and Associated Factors Among Teenage Adolescent Girls in Resource-poor Settings: A Cross-sectional Study
}

This article was published in the following Dove Press journal: Risk Management and Healthcare Policy

Jitendra Kumar Singh, (D) ${ }^{1, *}$ Dilaram Acharya, iD ${ }^{2,3, *}$ Divya Rani, ${ }^{4, *}$ Salila Gautam, ${ }^{5}$ Kalpana Thapa Bajgain, (D) ${ }^{6}$ Bishnu Bahadur Bajgain, (D) ${ }^{7}$ jiHyuk Park, (iD ${ }^{2}$ Seok-Ju Yoo, (iD ${ }^{2}$ Thomas G Poder, 8,9 Antoine Lewin, ${ }^{10,11}$ Kwan Lee ${ }^{2}$

'Department of Community Medicine and Public Health, Janaki Medical College, Tribhuvan University, Janakpur, Nepal; ${ }^{2}$ Department of Preventive Medicine, College of Medicine, Dongguk University, Gyeongju, Republic of Korea; ${ }^{3}$ Department of Community Medicine, Kathmandu University, Devdaha Medical College and Research Institute, Rupandehi, Nepal; ${ }^{4}$ Department of Community Medicine, Institute of Medical Sciences, Banaras Hindu University, Varanasi, India; ${ }^{5}$ Department of Public Health, Sanjeevani College of Medical Sciences, Purbanchal University, Rupandehi, Nepal; ${ }^{6}$ Aabka Research \& Consultancy, Calgary, Alberta, Canada; ${ }^{7}$ Department of Community Health Sciences, Cumming School of Medicine, University of Calgary, Calgary, Alberta, Canada; ${ }^{8}$ School of Public Health, University of Montreal, Montreal, Canada; ${ }^{9}$ Centre de Recherche de I'Institut Universitaire en Santé Mentale de Montréal, CIUSSS de l'Est-de-Lîile-de-Montréal, Montreal, Canada; ${ }^{10}$ Medical Affairs and Innovation, Héma-Québec, Montreal, Quebec, Canada; "Faculty of Medicine and Health Science, Sherbrooke University, Sherbrooke, Quebec, Canada

*These authors contributed equally to this work

Correspondence: Seok-Ju Yoo Department of Preventive Medicine, College of Medicine, Dongguk University, I23 Dongdae-Ro, Gyeongju-si 38066, Republic of Korea

Tel +82-10-87|2-6730

Fax +82-54-770-2825

Email medhippo@dongguk.ac.kr
Background and Purpose: Understanding the undernutrition status of teenage adolescent girls living in urban slums and its associated factors is meaningful to formulate customized health strategies. This study aimed to determine the prevalence of being underweight and associated factors among teenage adolescent girls in urban slums.

Materials and Methods: In this cross-sectional study, we enrolled a total of 418 teenage adolescent girls from five of 210 urban slums of Varanasi district, Uttar Pradesh, India employing two-stage probability sampling for the selection of households and subjects, between September 2016 and July 2017. The study of underwight subjects was assessed with BMI for age using standard criteria. Factors associated with being underweight were determined by multivariable logistic regression analysis.

Results: Of 418 study subjects, 49.76\% (208/418) were underweight. Results revealed that sociodemographic factors such as teenage adolescent girls who were from SC/ST (schedule caste/schedule tribe) caste/ethnicity (adjusted odds ratio $(\mathrm{AOR})=2.02,95 \% \mathrm{CI}: 1.00-4.23$ ), subjects whose father's education level was primary or lower $(\mathrm{AOR}=1.87,95 \% \mathrm{CI}: 1.12-3.11)$, and number of people in the family $>4(\mathrm{AOR}=2.18,95 \% \mathrm{CI}$ : $1.18-4.03)$ were associated with being underweight. Likewise, dietary behavior-related factors such as vegetarian $(\mathrm{AOR}=2.21,95 \% \mathrm{CI}$ : 1.25-3.92), and $<3$ meals per day ( $\mathrm{AOR}=2.36,95 \% \mathrm{CI}$ : $1.40-3.98$ ) than their counterparts were associated with being underweight. In addition, teenage adolescent girls from food-insecure households ( $\mathrm{AOR}=3.33,95 \% \mathrm{CI}$ : 2.01-5.51) were more likely to be underweight than those from food-secure households.

Conclusion: The higher burden of underweight among teenage adolescent girls in Indian urban slums needs to be addressed through specific public health interventions such as by improving education, providing education regarding dietary behavior, and having access to sufficient, safe, and nutritious foods.

Keywords: cross-sectional study, teenage girls, urban slums, undernutrition, underweight, India

\section{Introduction}

Undernutrition is a universal health concern that affects mainly children and adolescents from low- and-middle-income countries (LMICs). ${ }^{1,2}$ Undernutrition occurs as a result of insufficient macro- and micronutrient intakes and manifests in four forms: wasting, underweight, growth stunting, and nutritional deficiencies. ${ }^{1}$ According to a World Bank report, India accounts for more of the world's undernourished children than any other country, which has huge consequences on childhood and adolescent morbidity and mortality and the national economy. ${ }^{3}$ A study being conducted across 
eight Indian mega-cities among women with a specific focus on slum-non-slum demonstrated that being underweight was significantly higher in slum dwellers, while being overweight was notably higher in non-slum areas. ${ }^{4}$ A number of previous Indian studies ${ }^{5-7}$ frequently reported higher percentages (range: $16 \% \sim 30 \%$ ) of being underweight among slum-resident adolescent girls from different urban areas.

Adolescents (10-19 years old) comprise one quarter of the world's population. ${ }^{8,9}$ This time of life is critically important because it is during this period that rapid growth and development occurs, and thus, adolescents require higher nutrient intakes. ${ }^{10,11}$ Furthermore, health and food behaviors are shaped during this period, ${ }^{12,13}$ and thus, adolescents are more vulnerable to health and nutrition concerns than other age groups. More importantly, adolescent girls need good quality nutritive foods in sufficient quantity to cope with the added nutritional requirements associated with onset of maturity, menstruation, participation in various physical activities, ${ }^{14,15}$ and to reduce health risks and break the intergenerational cycle of malnutrition. ${ }^{16,17}$

Researchers in recent studies overlooked several important predictors of underweight adolescent girls such as sociodemographic and socioeconomic factors, ${ }^{18,19}$ parental education,${ }^{18,20}$ occupation, ${ }^{20}$ dietary habits ${ }^{5,18}$ and food insecurity. ${ }^{21,22}$ It is well known that being underweight is one of the major public health concerns in teenage adolescent, especially school-aged children in South East Asian countries as it impacts health, cognition, and educational achievements. ${ }^{3,23}$ Moreover, it is well-known that the poor health and adverse nutritional wellbeing of teenage adolescent girls can have farreaching consequences of intergenerational cycle of malnutrition, productivity, and economy losses.

In the current study setting of the urban slums of Varanasi, Uttar Pradesh, India, data depicted the poor health and wellbeing measures, ${ }^{24}$ and to the best of researchers' knowledge, scarce research has been performed of this kind in the current study settings. Although researchers have addressed the relation between adolescent girls' nutritional status and their associates in many Indian resource-poor settings, understanding the underweight status among teenage adolescent girls living in urban slums and its associated factors is meaningful to formulate evidence-based customized preventative and promotional strategies. The aim of this study was to determine the prevalence of underweight teenage adolescent girls and to identify associated factors among those residing in the urban slums of Varanasi district, India.

\section{Materials and Methods}

\section{Study Design, Setting, and Participants}

This community-based, cross-sectional study was conducted among teenage adolescent girls residing in five of 210 urban slums in Varanasi, Uttar Pradesh, India. Inhabitants of these slums lack basic amenities, such as adequate housing, electricity, and access to safe drinking water. We employed a two-stage probability sampling design to select a community-based sample. At first, we identified the total number of slums at different locations in Varanasi district from a list obtained from the Varanasi Slum Profile at Glance report 2011. ${ }^{25}$ There are a total of 210 slums in the district situated in five different locations, namely-nonhazardous or nonobjectionable sites, proximity to railway lines, near major nallahs/river, along water body bank or bed, and hazardous areas. ${ }^{26}$ Of these, we selected one slum from each of these five locations using simple random sampling method. The households' size of these selected slums ranged from 200 to 1200 households. The Second, we identified the required number of households per slums by using probability proportion to size (PPS). A systematic random sampling method was employed to select the households. Finally, teenage adolescent girls (aged 13 to 19 years) were enrolled from selected households. Only one adolescent girl was selected from each household randomly by using a lottery method when there was more than one. Sample size was estimated by using the formula; $\mathrm{n}=(\mathrm{Z} 1-\alpha / 2) 2 \mathrm{P} * \mathrm{Q} / \mathrm{L}^{2}$, assuming a prevalence of being underweight of $42.6 \%$ among adolescent girls, ${ }^{27}$ and a nonresponse of $10 \%$. As a result, the required sample size was estimated to be 414 . Finally, we enrolled the sample to 418 teenage adolescent girls. We sought the help of local community health volunteers in areas, such as Anganwadi/trained dais, during the recruitment process. Of 440 teenage adolescent girls invited to participate, 418 consented (a response rate of 94.56\%). Subjects with mental intellectual disability, developmental delay, autism, or any other condition that inhibited communication or the ability to participate in the study were excluded. Details of the study settings, participants, and other methodological details are described elsewhere. ${ }^{28}$

\section{Data Collection}

Data were collected between September 2016 and July 2017 by five nursing graduates using a structured and semi-structured questionnaire. In order to ensure the quality of data collected, two days of training were provided to 
all research assistants before data collection and their performance was monitored. The prepared English version questionnaire was thoroughly checked, pretested in the neighboring district, and necessary modifications were made as required. Questionnaires were translated into the local language (Hindi) and then back-translated into English to ensure translations were accurate. The survey questionnaire was composed of three parts: (1) personal profile (sociodemographic and socioeconomic characteristics, dietary behavior), (2) household food security, and (3) mental health states. Anthropometric measurements (height and weight) of the participants were measured by standard techniques and appropriate landmarks. ${ }^{29,30}$ Accordingly, weight was measured to the nearest $0.1 \mathrm{~kg}$ using a portable weighing machine (Libra, Libra Weighing Machine Limited, Bangkok, Thailand) and height was measured to the nearest $0.1 \mathrm{~cm}$ using anthropometer (Hindustan Minerals, The Hindustan Mineral Products Co. Ltd, Kolkata, India). The subjects were in light clothes and asked to remove their footwear before measuring height and weight. The scales were re-calibrated after each measurement. Accuracy of the scales was verified from time to time against known weights.

\section{Definition of Variables Dependent Variable}

Underweight status of study subjects was determined as weight in kilograms divided by height in squared meter and converted to a standard deviation score for pre-adults using standards recommended by Cole et al. ${ }^{31,32}$ Scores were classified as normal weight as 0 and overweight and obesity as +1 and +2 , respectively, while thinness grades 1 , 2 , and 3 were coded as $-1,-2$, and -3 . Due to a small number of subjects in the various categories, participants were further classified as presence of underweight (scores between -1 and -3 ) and absence of underweight (scores between 0 and 3 ).

\section{Independent Variables}

Sociodemographic and Socioeconomic Variables

All sociodemographic variables such as age, religion, caste/ ethnicity, type of family, head of family, number of people in the family, number of siblings, duration of residence in slums, family income, and educational levels and occupations of subjects and their parents were categorized as previously described. $^{28}$ Socioeconomic (SES) status was determined using the modified Kuppuswamy scale (updated in January 2017), which includes five categories based on scores; lower class $<5$, upper lower 5-10, lower middle 11-15, upper middle 16-25, and upper class 26-29. ${ }^{33}$ Because of the large number of participants in the lower class, it was further classified as: lower (lower and upper), middle (lower middle and upper middle) and upper. ${ }^{34}$

\section{Dietary Behavior}

The variables related to dietary behavior were as follows: nature of diet (vegetarian: those who consumed diet included milk, dairy products and eggs for at least one year)/nonvegetarian or omnivorous: those who ate meat, including poultry and fish, at least once a week), ${ }^{35}$ timings of meals (irregular: those who did not eat any of the regular meal-breakfast, lunch or dinner within two hours time interval for at least one week in the previous month/ fixed: those who ate any of the regular meals - breakfast, lunch or dinner within two hours time interval for at least one week in the previous month), frequency of meals per day ( $<3$ vs $\geq 3$ ), washing practice for green leafy vegetable (after cutting/before cutting). Types of flour used were classified as sieved (without choker) or unsieved (with choker). ${ }^{36}$ Intakes of food items

were determined using a food frequency questionnaire $(\text { FFQ })^{37}$ as; daily 2-3 days per week, once a week, sometimes, or occasionally or never. For our analysis, it was further divided into two categories based on consumption patterns. Intake of pulses, green leafy vegetables, other vegetables, and milk were categorized as daily and $\geq$ once a week, whereas consumptions of fruits and meat and meat products were categorized as sometimes/occasionally and $\geq$ once a week.

\section{Household Food Security and Mental Health Status}

We adopted The Household Food Insecurity Access Scale (HFIAS) to evaluate food security. ${ }^{38}$ This scale classifies individuals into four levels of household food insecurity based on subject recall over the past 30 days: food-secure or mildly, moderately or severely food-insecure. We asked respondents to answer these questions with yes or no response options during the previous four weeks of date of data collection. For those who answered "yes" to a question, a frequency-of-occurrence question was asked, and responses were categorized as: rare (once or twice; response code 1), sometimes (three to 10 times; response code 2), or often (more than 10 times; response code 3 ). HFIAS scores were used as continuous measures of degrees of household food insecurity and were calculated by summing scores for frequency-of-occurrence 
questions for each household. The maximum score for a household was 27 , if responded to all nine frequency-ofoccurrence questions with a response code of 3 and the minimum score was 0 , if the individual answered "no" to all frequency-of-occurrence questions. Thus, higher scores indicated greater food insecurity. ${ }^{38}$ Furthermore, the nine food insecurity occurrence questions and nine frequency of occurrence questions were asked to determine how frequently the condition mentioned in the occurrence question occurred. The questionnaire sought the main components of food insecurity, such as, (1) anxiety and uncertainty about household food supply, (2) insufficient quality of food (included food varieties and preferences), and (3) insufficient food intake and its physical consequences.

In order to assess the mental health status of the study subjects, we employed four components of the Mental Health Inventory: anxiety, depression, loss of behavioral control, and psychological distress. These components were further categorized as low, medium or high. The scores were classified as: (1) for anxiety, low 9-24, medium 25-39, and high 40-54; (2) for depression, low 4-10, medium 11-16, and high 17-23; (3) for loss of behavior control, low 9-22, medium 23-38, and high 39-53; and (4) for psychological distress, low 24-60, medium 61-100, and high $105-142 .{ }^{39-41}$ Since the proportion of participants in the low category was either very small or zero, we merged low categories into the medium category, and considered one category "low/medium", and logistic regressions were run (low/medium vs high) as binary outcomes. The details of food insecurity and mental health status measurement is available from our previous publication. ${ }^{28}$

\section{Statistical Analysis}

Data were first entered into EpiData 3.1 and then transferred to SPSS for Windows V. 22.0 (IBM Corporation, Armonk, NY, USA) for the analysis. Multivariable logistic regression was employed to assess associations between independent and outcome variables. We used regression diagnostic procedures to check evidence of multicollinearity or overly influential outliers in the model. However, we did not detect any multicollinearity or overly influential outliers. All variables determined to be important $(p<0.10)$ by univariate analysis were incorporated into the multivariable logistic regression analysis by backward elimination to adjust for simultaneous effects of multiple factors and to control the effects of confounding variables on the response variable. Results are expressed as odds ratios
(ORs) with 95\% confidence intervals for binary nutritional status outcomes. All tests were two-tailed and $p$-values of $<0.05$ were deemed statistically significant.

\section{Ethics}

Ethical approval was obtained from the Ethical Committee of Banaras Hindu University, India (approval number: ECR/526.Inst/UP/2014 Dt.31.1.14). Written informed consent was obtained from either the study subjects who were $\geq 18$ years of age or from their parents for all those who were $<18$ years of age after providing them with comprehensive information about the study. It was made clear to participants that they could leave the study at any time and decide not to respond to any questionnaire. All personal details were removed from files before data analysis.

\section{Results}

\section{Underweight, Sociodemographic, Socioeconomic Characteristics, Dietary Behaviors, Household Food Insecurity and Mental Health Status of the Study Subjects}

Of 418 participants, $49.76 \%$ (208/418) were underweight. Of total subjects, slightly more than half $(52.0 \%)$ of the underweight participants were 17-19 years old, of other backward (OBC) caste/ethnicity (56.7\%), from nuclear family $(50.2 \%)$, were of residence in the slums for $\leq 30$ year $(49.9 \%)$, subjects educated to primary level or less $(52.3 \%)$, and subjects with mothers in the home maker occupation (50.3\%) (Table 1).

The result of univariate analysis showed that the study participants' sociodemographic and socioeconomic factors such as subjects with more than four family members in the family, having more than two siblings, working outside (service, business, labor), subjects with parents educated to primary level or less, a father working in agriculture or as a laborer, a family income and socioeconomic status in the first tercile or lower had significantly higher rates of underweight than their counterparts (Table 1). Likewise, the factors related to dietary behavior and intake of food significantly associated with underweight adolescent girls were: vegetarians, irregular intake of meal, meal frequency less than three times/day, washing green leafy vegetables after cutting, intake of vegetables only $\geq$ once a week, and fruit, and meat and meat products consumption sometimes/ occasionally (Table 2). Our study also revealed the 
Table I Association Between Being Underweight and Sociodemographic and Socioeconomic Characteristics of Adolescent Girls Living in Resource-poor Settings

\begin{tabular}{|c|c|c|c|c|}
\hline \multirow[t]{2}{*}{ Sociodemographic Characteristics } & \multirow[t]{2}{*}{ Total $n=4 \mid 8$ (\%) } & \multicolumn{2}{|l|}{ Underweight } & \multirow[t]{2}{*}{ OR (95\%Cl) } \\
\hline & & Yes n=208 (\%) & No $n=210$ (\%) & \\
\hline \multicolumn{5}{|l|}{ Age } \\
\hline $13-16$ years & $216(51.7)$ & $103(47.7)$ & II $3(52.3)$ & $0.84(0.57-1.23)$ \\
\hline $17-19$ Years & $202(48.3)$ & $105(52.0)$ & $97(48.0)$ & Reference \\
\hline \multicolumn{5}{|l|}{ Religion } \\
\hline Hindu & $404(96.7)$ & $20 \mathrm{I}(49.8)$ & $203(50.2)$ & $0.99(0.34-2.87)$ \\
\hline Muslim & $14(3.3)$ & $7(50.0)$ & $7(50.0)$ & Reference \\
\hline \multicolumn{5}{|l|}{ Caste/ethnicity } \\
\hline SC/ST (schedule caste/schedule tribe) & $20 \mathrm{I}(48 . \mathrm{I})$ & $93(46.3)$ & $108(54.7)$ & I.I2 (0.63-2.0I) \\
\hline OBC (other backward caste) & $157(37.6)$ & 89 (56.7) & $68(43.3)$ & I.7I (0.93-3.12) \\
\hline General (upper caste group) & $60(14.3)$ & $26(43.3)$ & $34(56.7)$ & Reference \\
\hline \multicolumn{5}{|l|}{ Type of family } \\
\hline Joint & $89(21.3)$ & $43(48.3)$ & $46(51.7)$ & $0.92(0.58-1.48)$ \\
\hline Nuclear & $329(78.7)$ & $165(50.2)$ & $164(49.8)$ & Reference \\
\hline \multicolumn{5}{|l|}{ Head of family } \\
\hline Male & $374(89.5)$ & $187(50.0)$ & $187(50.0)$ & $1.09(0.58-2.04)$ \\
\hline Female & $44(10.5)$ & $21(47.7)$ & $23(52.3)$ & Reference \\
\hline \multicolumn{5}{|l|}{ Number of people in family } \\
\hline$>4$ & $334(79.9)$ & $177(53.0)$ & $157(47.0)$ & $1.92(1.17-3.15)^{* *}$ \\
\hline$\leq 4$ & $84(20.1)$ & $31(36.9)$ & $53(63.1)$ & Reference \\
\hline \multicolumn{5}{|l|}{ Number of siblings } \\
\hline$>2$ & $306(73.2)$ & $165(53.9)$ & $|4|(46.1)$ & $1.87(1.20-2.92)^{* *}$ \\
\hline$\leq 2$ & $112(26.8)$ & $43(38.4)$ & $69(61.6)$ & Reference \\
\hline \multicolumn{5}{|l|}{ Duration of resident in slum } \\
\hline$\leq 30$ year & $405(96.9)$ & $202(49.9)$ & $203(50.1)$ & $1.16(0.38-3.5 I)$ \\
\hline$>30$ year & $13(3.1)$ & $6(46.2)$ & $7(53.8)$ & Reference \\
\hline \multicolumn{5}{|l|}{ Education of subject } \\
\hline Primary and lower & $149(35.6)$ & $78(52.3)$ & 7I (47.7) & I.I7 (0.78-I.75) \\
\hline Secondary and more & $269(64.4)$ & I $30(48.3)$ & $139(51.7)$ & Reference \\
\hline \multicolumn{5}{|l|}{ Education of mother $(n=408)$} \\
\hline Primary and lower & $278(68.1)$ & $157(56.5)$ & $|2|(43.5)$ & $2.21(1.44-3.40)^{* * * *}$ \\
\hline Secondary and more & $130(31.9)$ & $48(36.9)$ & $82(63.1)$ & Reference \\
\hline \multicolumn{5}{|l|}{ Education of father $(n=379)$} \\
\hline Primary and lower & $165(43.5)$ & $100(60.6)$ & $65(39.4)$ & $2.24(1.48-3.40)^{* * *}$ \\
\hline Secondary and more & $214(56.5)$ & $87(40.7)$ & $127(59.3)$ & Reference \\
\hline \multicolumn{5}{|l|}{ Occupation of subjects } \\
\hline Working outside (service, business, labor) & $58(13.9)$ & $38(65.5)$ & $20(34.5)$ & $2.12(1.18-3.79)^{*}$ \\
\hline Student & $360(86.1)$ & $170(47.2)$ & $190(52.8)$ & Reference \\
\hline \multicolumn{5}{|l|}{ Occupation of mother $(n=408)$} \\
\hline Working outside (service, business, labor) & $90(22.1)$ & $45(50.0)$ & $45(50.0)$ & $0.98(0.6 \mathrm{I}-\mathrm{I} .57)$ \\
\hline Homemaker & $318(77.9)$ & $160(50.3)$ & $158(49.7)$ & Reference \\
\hline
\end{tabular}

(Continued) 
Table I (Continued).

\begin{tabular}{|c|c|c|c|c|}
\hline \multirow[t]{2}{*}{ Sociodemographic Characteristics } & \multirow[t]{2}{*}{ Total $n=4 \mid 8(\%)$} & \multicolumn{2}{|l|}{ Underweight } & \multirow[t]{2}{*}{ OR $(95 \% \mathrm{Cl})$} \\
\hline & & Yes $n=208(\%)$ & No $n=210(\%)$ & \\
\hline \multicolumn{5}{|l|}{ Occupation of father $(n=379)$} \\
\hline Agriculture/labor & $124(32.7)$ & $76(61.3)$ & $48(38.7)$ & $2.95(1.32-3.18)^{* *}$ \\
\hline Service/business & $255(67.3)$ & III (43.5) & $144(56.5)$ & Reference \\
\hline \multicolumn{5}{|l|}{ Family income } \\
\hline First tercile & $156(37.3)$ & $103(66.0)$ & $53(34.0)$ & $3.15(1.95-5.07)^{* * *}$ \\
\hline Second tercile & $123(29.4)$ & $52(42.3)$ & $71(57.7)$ & $1.18(0.72-1.95)$ \\
\hline Third tercile & $139(33.3)$ & $53(38.1)$ & $86(61.9)$ & Reference \\
\hline \multicolumn{5}{|l|}{ Socioeconomic status } \\
\hline Lower (lower/upper lower) & $200(47.8)$ & $128(64.0)$ & $72(36.0)$ & $2.48(1.30-4.73)^{* *}$ \\
\hline Middle (lower middle/upper middle) & $170(40.7)$ & $60(35.3)$ & $110(64.7)$ & $0.76(0.39-1.46)$ \\
\hline Upper & 48 (II.5) & $20(4 I .7)$ & $28(58.3)$ & Reference \\
\hline
\end{tabular}

Notes: ${ }^{*} p<0.05 ; *_{p}<0.005 ; * * * p<0.0001$.

association of household food insecurity and mental health states with underweight among adolescent girls in univariate analysis. Accordingly, adolescent girls with household food insecurity, those with high level of anxiety, depression, loss of behavioral control and psychological distress were significantly associated with being underweight (Table 3).

\section{Associations Between Being Underweight and Sociodemographic Variables, Dietary Behavior, and Household Food Insecurity}

Table 4 shows multivariable logistic regression analysis results for being underweight among the study subjects. Teenage adolescent girls who were from SC/ST (schedule caste/schedule tribe) caste/ethnicity were more likely to $(\mathrm{AOR}=2.02,95 \% \mathrm{CI}: 1.00-4.23)$ to be underweight than general (upper caste group). Subjects whose father's education level was primary or lower $(\mathrm{AOR}=1.87,95 \% \mathrm{CI}$ : 1.12-3.11) had higher odds of being underweight than those whose father's education level was secondary and higher. In addition, vegetarians than nonvegetarians $(\mathrm{AOR}=2.21,95 \% \mathrm{CI}: 1.25-3.92)$, and those who consumed $<3$ meals a day than those who consumed $\geq 3$ meals a day $(\mathrm{AOR}=2.36,95 \% \mathrm{CI}: 1.40-3.98)$, number of people in family $>4$ vs $\leq 4 \quad(\mathrm{AOR}=2.18,95 \% \mathrm{CI}: 1.18-4.03)$ were found to have higher odds of being underweight. Similarly, teenage adolescent girls from food-insecure households ( $\mathrm{AOR}=3.33$, 95\%CI: 2.01-5.51) were more likely to be underweight than those from food-secure households.

\section{Discussion}

This study shows that half of the teenage adolescent girls, $49.76 \%$ (208/418) living in the selected urban slums of Varanasi district, India, were underweight, and that teenage adolescent girls who were from schedule caste/schedule tribe caste/ethnicity, those with a father educated to a primary level or lower, having more than four people in the family, with a vegetarian diet, those who consumed fewer than three meals per day, and those with household food insecurity were found to have higher odds of being underweight.

Undernutrition has been a major public health issue in India. According to UNICEF's 2011 State of the World's Children Report, undernutrition among teenage adolescent girls was higher (47\%) in India than in any other country. ${ }^{42}$ A recent Indian study cautioned that rates of malnutrition among adolescent girls, pregnant and lactating women, and children are alarmingly high and stated that the reasons for higher rates among nutritionally vulnerable populations were maternal nutritional status and lactation behavior, women's education, and sanitation. ${ }^{43}$ In our study, we found half of the teenage adolescent girls were underweight, which is consistent with another study performed in a similar setting, ${ }^{44}$ but this differs from the rates found in a study conducted in urban slums in South India based on National Center for Health Statistics (NCHS) and Indian standards measurements $\left(42.6 \%\right.$ and $22.9 \%$, respectively). ${ }^{27}$ A study in several African countries reported substantially lower prevalence of undernutrition among adolescent girls than that found in the present study. ${ }^{45}$ These varied results among various countries 
Table 2 Associations Between Being Underweight and Dietary Behaviors Among Adolescent Girls in Resource-poor Settings

\begin{tabular}{|c|c|c|c|c|}
\hline \multirow[t]{2}{*}{ Dietary Behavior and Intake of Food } & \multirow[t]{2}{*}{ Total $n=418$ (\%) } & \multicolumn{2}{|l|}{ Underweight } & \multirow[t]{2}{*}{ OR $(95 \% \mathrm{Cl})$} \\
\hline & & Yes $n=208(\%)$ & No $n=210(\%)$ & \\
\hline \multicolumn{5}{|l|}{ Nature of diet } \\
\hline Vegetarian & $103(24.6)$ & $60(58.3)$ & $43(4 \mid .7)$ & $1.57(1.00-2.46)^{*}$ \\
\hline Nonvegetarian & $315(75.4)$ & I $48(47.0)$ & $167(53.0)$ & Reference \\
\hline \multicolumn{5}{|l|}{ Timing of meal } \\
\hline Irregular & $260(62.2)$ & $153(58.8)$ & $107(4 \mid .2)$ & $2.67(1.77-4.03)^{* * *}$ \\
\hline Fixed & $158(37.8)$ & $55(34.8)$ & $103(65.2)$ & Reference \\
\hline \multicolumn{5}{|l|}{ Frequency of meal (per day) } \\
\hline$<3$ & $145(34.7)$ & I0I (69.7) & $44(30.3)$ & $3.56(2.31-5.47)^{* * *}$ \\
\hline$\geq 3$ & $273(65.3)$ & $107(39.2)$ & $166(60.8)$ & Reference \\
\hline \multicolumn{5}{|l|}{ Types of flour used } \\
\hline Sieved (without choker) & $339(8 I .1)$ & $176(5 \mid .9)$ & $163(48.1)$ & $1.58(0.96-2.60)$ \\
\hline Unsieved (with choker) & $79(18.9)$ & $32(40.5)$ & $47(59.5)$ & Reference \\
\hline \multicolumn{5}{|l|}{ Washing of green/leafy vegetable } \\
\hline After cutting & $157(37.6)$ & $95(60.5)$ & $62(39.5)$ & $2.00(1.34-3.00)^{* *}$ \\
\hline Before cutting & $261(62.4)$ & $113(43.3)$ & I 48 (56.7) & Reference \\
\hline \multicolumn{5}{|l|}{ Intake of pulses } \\
\hline$\geq$ once a week & $90(2 \mid .5)$ & $43(47.8)$ & $47(52.2)$ & $0.90(0.56-1.44)$ \\
\hline Daily & $328(78.5)$ & $165(50.3)$ & $163(49.7)$ & Reference \\
\hline \multicolumn{5}{|l|}{ Intake of green leafy vegetables } \\
\hline$\geq$ once a week & $342(81.8)$ & $175(5 \mid .2)$ & $167(48.8)$ & $1.36(0.82-2.25)$ \\
\hline Daily & $76(18.2)$ & $33(43.4)$ & $43(56.6)$ & Reference \\
\hline \multicolumn{5}{|l|}{ Intake of other vegetables } \\
\hline$\geq$ once a week & $348(83.3)$ & $181(52.0)$ & $167(48.0)$ & $1.72(1.02-2.91)^{*}$ \\
\hline Daily & $70(16.7)$ & $27(38.6)$ & $43(6 I .4)$ & Reference \\
\hline \multicolumn{5}{|l|}{ Milk consumption } \\
\hline$\geq$ once a week & $359(85.9)$ & I84 (5I.3) & $175(48.7)$ & $1.53(0.87-2.66)$ \\
\hline Daily & $59(14.1)$ & $24(40.7)$ & $35(59.3)$ & Reference \\
\hline \multicolumn{5}{|l|}{ Fruits consumption } \\
\hline Sometimes/occasionally & $145(34.7)$ & $84(57.9)$ & $61(42.1)$ & $1.65(1.10-2.48)^{*}$ \\
\hline$\geq$ once a week & $273(65.3)$ & $124(45.4)$ & $149(54.6)$ & Reference \\
\hline \multicolumn{5}{|l|}{ Meat and meat product $(n=3 \mid 5)^{a}$} \\
\hline Sometimes/occasionally & $24 \mid(76.5)$ & $116(48.1)$ & $125(51.9)$ & $1.21(0.72-2.05)$ \\
\hline$\geq$ once a week & $74(23.5)$ & $32(43.2)$ & $42(56.8)$ & Reference \\
\hline
\end{tabular}

Notes: a Among nonvegetarian only, ${ }^{*} p<0.05 ; * * p<0.005 ;{ }^{* * *} p<0.0001$.

are probably due to the use of different measurement standards, study settings, and other study population attributes. However, it is already known that the inaccessible and hard to reach adolescent girls in terms of basic amenities and healthcare services in India such as those of rural residents, ${ }^{46,47}$ and urban slum dwellers ${ }^{27,44}$ are mainly suffering from undernutrition. Therefore, teenage adolescent girls residing in slum settings in India should be prioritized in terms of public health interventions, socioeconomic transformations, and community empowerment in order to reduce the long-standing problem of undernutrition.

We observed the caste/ethnicity as schedule caste/schedule tribe predicted underweight teenage adolescent girls. Previous reports have some conflicting views of the impact of ethnic minority as predictor of adolescents and children being underweight. ${ }^{48,49}$ A Chinese study indicated the 
Table 3 Associations Between Being Underweight, Household Food Insecurity, and Mental Health Status Among Adolescent Girls in Resource-poor Settings

\begin{tabular}{|c|c|c|c|c|}
\hline \multirow[t]{2}{*}{ Household Food Insecurity and Mental Health Status } & \multirow[t]{2}{*}{ Total $n=418$ (\%) } & \multicolumn{2}{|l|}{ Underweight } & \multirow[t]{2}{*}{ OR $(95 \% \mathrm{Cl})$} \\
\hline & & Yes $n=208(\%)$ & No $n=210$ (\%) & \\
\hline \multicolumn{5}{|l|}{ Households food security } \\
\hline Food insecure & $199(47.6)$ & $137(68.8)$ & $62(31.2)$ & $4.60(3.05-6.95)^{*}$ \\
\hline Food secure & $219(52.4)$ & $71(32.4)$ & $148(67.6)$ & Reference \\
\hline \multicolumn{5}{|l|}{ Anxiety } \\
\hline High & $150(35.9)$ & $101(67.3)$ & $49(32.7)$ & $3.10(2.03-4.71)^{*}$ \\
\hline Low/medium & $268(64.1)$ & $107(39.9)$ & $161(60.1)$ & Reference \\
\hline \multicolumn{5}{|l|}{ Depression } \\
\hline High & $177(42.3)$ & II $5(65.0)$ & $62(35.0)$ & $2.95(1.97-4.4 I)^{*}$ \\
\hline Low/medium & $241(57.7)$ & $93(38.6)$ & $148(6 \mid .4)$ & Reference \\
\hline \multicolumn{5}{|l|}{ Loss of behavior control } \\
\hline High & $240(57.4)$ & $139(57.9)$ & $101(42.1)$ & $2.17(1.46-3.22)^{*}$ \\
\hline Low/medium & $178(42.6)$ & $69(38.8)$ & $109(6 \mid .2)$ & Reference \\
\hline \multicolumn{5}{|l|}{ Psychological distress } \\
\hline High & I74 (4I.6) & $110(63.2)$ & $64(36.8)$ & $2.56(1.7 \mathrm{I}-3.82)^{*}$ \\
\hline Low/medium & $244(58.4)$ & $98(40.2)$ & $146(59.8)$ & Reference \\
\hline
\end{tabular}

Note: $*_{p}<0.0001$.

burden of excess body weight was higher than that of being underweight in minority girls aged 7-18 years, while a Nepalese study ${ }^{49}$ being conducted in a nationally representative adolescent population reported that the Dalit minority ethnic group had lower odds of being thin. Nonetheless, the caste/ethnic-specific efforts are necessary to improve the status of being underweight during adolescence. A lower level of parenteral education positively influenced the occurrence of being underweight among adolescent girls in other studies. ${ }^{18,20}$ In line with these previous findings, we also found the paternal education primary or lower level increased the risk of thinness, possibly because parenteral education appears to play a crucial role in providing adequate quantities and qualities of food to children. ${ }^{50,51}$ Family size has been shown to have both a positive and negative impact on children and adolescence nutritional status in some previous studies.52,53 We identified an increasing family size $(>4)$ had higher odds of being underweight in our study subjects. However, there is no biologically plausible mechanism for the effect of family size on the underweight status of adolescent girls. It may be argued that increasing family size might cause decreasing family expenditure in matters relating to health, and poor nutritional access in the family leading to underweight status. It would therefore, be imperative to recommend the sociodemographic attributes such ase parental education, family size, and the existing caste-based system be considered while designing the nutritional intervention in order to reduce the prevalent incidence of being underweight among teenage adolescent girls in resource-poor settings.

Interestingly, this study revealed that teenage adolescent girls who were vegetarians and had fewer than three meals per day were at significantly higher risk of being underweight. A previous study reported vegetarian adolescent girls were less likely to consume recommended levels of fat, cholesterol, and micronutrients than those with an omnivorous diet, which supports the notion that vegetarian adolescent girls are more at risk of undernutrition. ${ }^{35}$ Other studies have also consistently demonstrated a low meal frequency (fewer than two meals/day) ${ }^{18}$ and irregular meal times $^{54}$ are risk factors of being underweight among adolescent girls. Moreover, household food insecurity has been demonstrated to be a major risk factor, especially during the adolescent period. ${ }^{28,55}$ An Ethiopian study concluded household food insecurity among girls was associated with a higher frequency of illness and poor work performance due to poor health, tiredness, and lack of energy. ${ }^{55}$ Furthermore, stressed, food-insecure individuals are likely to change their dietary behaviors, and thus increase the risk of being thin. ${ }^{56,57}$ Since household food insecurity is more common in low-income and deprived 
Table 4 Multivariable Logistic Regression Analysis of the Association Between Sociodemographic Variables, Dietary Behaviors, and Household Food Insecurity and the Risk of Being Underweight Among Adolescent Girls in Resource-poor Settings

\begin{tabular}{|c|c|c|}
\hline Characteristics & Category & AOR $(95 \% \mathrm{Cl})$ \\
\hline Caste/ethnicity & $\begin{array}{l}\text { SC/ST (schedule caste/ } \\
\text { schedule tribe) } \\
\text { OBC (other backward caste) } \\
\text { General (upper caste group) }\end{array}$ & $\begin{array}{l}2.02(1.00-4.23)^{*} \\
1.26(0.61-2.58) \\
\text { Reference }\end{array}$ \\
\hline Education of father & $\begin{array}{l}\text { Primary and lower } \\
\text { Secondary and more }\end{array}$ & $\begin{array}{l}1.87(1.12-3.11)^{*} \\
\text { Reference }\end{array}$ \\
\hline Nature of diet & $\begin{array}{l}\text { Vegetarian } \\
\text { Non vegetarian }\end{array}$ & $\begin{array}{l}2.21(1.25-3.92)^{* *} \\
\text { Reference }\end{array}$ \\
\hline $\begin{array}{l}\text { Number of people } \\
\text { in family }\end{array}$ & $\begin{array}{l}>4 \\
\leq 4\end{array}$ & $\begin{array}{l}2.18(1.18-4.03)^{*} \\
\text { Reference }\end{array}$ \\
\hline $\begin{array}{l}\text { Frequency of meal } \\
\text { intake/day }\end{array}$ & $\begin{array}{l}<3 \\
\geq 3\end{array}$ & $\begin{array}{l}2.36(1.40-3.98)^{* *} \\
\text { Reference }\end{array}$ \\
\hline Food security & $\begin{array}{l}\text { Food insecure } \\
\text { Food Secure }\end{array}$ & $\begin{array}{l}3.33(2.01-5.51)^{* * * *} \\
\text { Reference }\end{array}$ \\
\hline
\end{tabular}

Notes: All variables considered to be important $(p<0.10)$ in univariate analysis were entered into the multivariable logistic regression analysis. ${ }^{*} p<0.05$; ${ }^{* *} p<0.005$; $* * * p<0.0001$.

Abbreviation: AOR, adjusted odds ratio.

communities such as among the urban poor, those living in slums, and in the rural population, ${ }^{28,58-60}$ health and social measures/strategies must place greater emphasis on such resource-limited settings to reduce the established burden of undernutrition. Our univariate analysis showed a positively associated relation of all four mental health dimensions (high level of anxiety, depression, loss of behavior control, and psychological distress) with teenage adolescent girls' being underweight. However, we did not find such association in the final multivariable logistic regression analysis after adjustment of covariates. Several studies have reported the positive association between diet and being underweight with adolescent girl's mental health status. ${ }^{61-63}$ Nonetheless, we could not find literature that explicitly describes the causes of how mental health status affects the nutritional health status in teenage adolescent girls; It might be argued that the reverse causality be true in our case. In addition, it might also be hypothesized that chronic health conditions such as poor mental health outcomes may lead to household food insecurity; ${ }^{64}$ Household food insecurity thus might increase the incidence of being underweight.

This study is of particular importance and has some strengths. To be specific, it is one of the rare studies to investigate the association between undernutrition and mental health status, household food insecurity, dietary behaviors, and personal, social, and economic factors among teenage adolescent girls in the current study setting. Second, the subject response rate was very high (94.56\%). Third, already piloted tools were used to gather information. Nevertheless, the study also has its own limitations. First, the study might have suffered from recall bias as much information was collected based on subject self-reports. Second, the study could not capture in detail the influence of dietary diversity, and that of eating disorders on study outcomes. Future studies should understand the impact of dietary diversity, eating disorders and mental health status among others on nutritional status of teenage adolescent girls. Further larger-scale studies are required to identify the factors responsible for adolescent underweight in multiple urban slums across India in order to establish nationwide preventive and promotional strategies to reduce this age-old problem and its adverse health impacts.

\section{Conclusion}

This study shows that half of the teenage adolescent girls in urban slums of Varanasi, district, India, were underweight. The identified predictors of being underweight among teenage adolescent girls were: schedule caste/schedule tribe caste/ethnicity, paternal education a primary or lower, having more than four people in the family, a vegetarian diet, and fewer than three meals a day. In addition, we found household food insecurity to be independently associated with being underweight. Our findings demonstrate that the higher burden of being underweight among teenage adolescent girls in Indian slums need to be addressed through specific public health interventions such as by improving education, educating target populations to modify dietary behaviors, and having access to adequate amounts of safe, nutritious foods.

\section{Acknowledgment}

Authors contributed equally as joint first author: Jitendra Kumar Singh, Dilaram Acharya, and Divya Rani. 


\section{Disclosure}

The authors report no conflicts of interest in this work.

\section{References}

1. WHO World Health Organization. Malnutrition. World Health Organization. Available from: https://www.who.int/news-room/factsheets/detail/malnutrition. Accessed July 1, 2020

2. World Health Organization. Global prevalence of anaemia 2011; 2015. Available from: https://www.who.int/nutrition/publications/ micronutrients/global_prevalence_anaemia_2011/en/. Accessed December 3, 2020

3. The World Bank. Helping India combat persistently high rates of malnutrition. World Bank. Available from: https://www.worldbank. org/en/news/feature/2013/05/13/helping-india-combat-persistentlyhigh-rates-of-malnutrition. Accessed July 02, 2020

4. Gaur K, Keshri K, Joe W. Does living in slums or non-slums influence women's nutritional status? Evidence from Indian mega-cities. Soc Sci Med. 2013;77:137-146. doi:10.1016/j.socscimed.2012.11.017

5. Awasthi R, Srivastava A, Dixit AK, Sharma M. Nutritional status of adolescent girls in urban slums of Moradabad: a cross sectional study. Int J Community Med Public Health. 2016;3(1):276-280.

6. Bhattacharyya $\mathrm{H}$, Barua A. Nutritional status and factors affecting nutrition among adolescent girls in urban slums of Dibrugarh, Assam. Natl J Commun Med. 2013;4(1):35-39.

7. Bhattacharyya M, Sen P, Hazra S, Sinha RN, Sahoo SK, Panda AK. Prevalence of overweight and obesity among adolescent school girls in Urban Slum of Kolkata. children. 2012;3:4.

8. Clifton D, Hervish A. The World's Youth 2013 Data Sheet. Washington, DC: Population Reference Bureau; 2013.

9. World Health Organization. Progress in Reproductive Health Research. Geneva: World Health Organization; 2004:65.

10. Delisle H. Nutrition in Adolescence: Issues and Challenges for the Health Sector: Issues in Adolescent Health and Development. WHO; 2005.

11. Cordeiro L, Lamstein S, Mahmud Z, Levinson FJ. Adolescent malnutrition in developing countries: a close look at the problem and at two national experiences. SCN News. 2006;31:6-13.

12. Dennison CM, Shepherd R. Adolescent food choice: an application of the theory of planned behaviour. J Hum Nutr. 1995;8(1):9-23.

13. Videon TM, Manning CK. Influences on adolescent eating patterns: the importance of family meals. J Adolesc Health. 2003;32(5):365373. doi:10.1016/S1054-139X(02)00711-5

14. Spear BA. Adolescent growth and development. Research support, $U$ S Gov't, P H S. J Am Diet Assoc. 2002;102(3 Suppl):90418-90419. doi:10.1016/S0002-8223(02)90418-9

15. Story M, Hermanson J. Nutrient needs during adolescence and pregnancy. Nutr Pregnant Adolesc. 2000;37-46.

16. Mitchell K. Adolescent sexual and reproductive health a toolkit for humanitarian setting, a companion to the inter-agency field manual on reproductive health in humanitarian settings. Save Child UNFPA. 2009.

17. Arlinghaus KR, Truong C, Johnston CA, Hernandez DC. An intergenerational approach to break the cycle of malnutrition. Curr Nutr Rep. 2018;7(4):259-267. doi:10.1007/s13668-018-0251-0

18. Gagebo DD, Kerbo AA, Thangavel T. Undernutrition and associated factors among adolescent girls in Damot Sore District, Southern Ethiopia. J Nutr Metab. 2020;2020:5083140. doi:10.1155/2020/5083140

19. Ahmad S, Shukla NK, Singh JV, Shukla R, Shukla M. Double burden of malnutrition among school-going adolescent girls in North India: a cross-sectional study. J Family Med Prim Care. 2018;7(6):14171424. doi:10.4103/jfmpc.jfmpc_185_18

20. Berhe K, Gebremariam G. Magnitude and associated factors of undernutrition (underweight and stunting) among school adolescent girls in Hawzen Woreda (District), Tigray regional state, Northern Ethiopia: cross-sectional study. BMC Res Notes. 2020;13(1):59. doi:10.1186/s13104-020-4926-4
21. Candler T, Costa S, Heys M, Costello A, Viner RM. Prevalence of thinness in adolescent girls in low- and middle-income countries and associations with wealth, food security, and inequality. J Adolesc Health. 2017;60(4):447-454.e1. doi:10.1016/j.jadohealth.2016.11.003

22. Hlaing LM, Htet MK, Dibley M, Lin H. Chronic undernutrition and food insecurity among children and adolescent girls in Myanmar (P04-052-19). Curr Dev Nutr. 2019;3(Supplement_1). doi:10.1093/ cdn/nzz051.P04-052-19

23. Best C, Neufingerl N, van Geel L, van den Briel T, Osendarp S. The nutritional status of school-aged children: why should we care? Food Nutr Bull. 2010;31(3):400-417. doi:10.1177/156482651003100303

24. Jha DK, Tripathi V. Quality of Life in Slums of Varanasi City: A Comparative Study. 2014.

25. Census of India. Varanasi slum profile at glance report, 2011; 2011. Available from: http://www.censusindia.gov.in/2011 census/censusda ta2k11.aspx

26. Slum free city plan of action. Varanasi: Ministry of Urban Development, Govt. of India; 2013.

27. Prashant K, Shaw C. Nutritional status of adolescent girls from an urban slum area in South India. Indian J Pediatr. 2009;76(5):501504. doi:10.1007/s12098-009-0077-2

28. Rani D, Singh JK, Acharya D, Paudel R, Lee K, Singh SP. Household food insecurity and mental health among teenage girls living in urban slums in Varanasi, India: a cross-sectional study. Int $J$ Environ Res Public Health. 2018;15(8):1585. doi:10.3390/ijerph15081585

29. Weiner JS, Lourie JA. Human Biology, a Guide to Field Methods. 1969.

30. Ermakova S, Podstavkina T, Strokina A. Anthropometric Atlas: Recommendations on Methods. National Bureau of Standards, US Department of Commerce, and the National; 1985.

31. Cole TJ, Flegal KM, Nicholls D, Jackson AA. Body mass index cut offs to define thinness in children and adolescents: international survey. $B M J$. 2007;335(7612):194. doi:10.1136/bmj.39238.399444.55

32. Cole TJ, Freeman JV, Preece MA. Body mass index reference curves for the UK, 1990. Arch Dis Child. 1995;73(1):25. doi:10.1136/adc.73.1.25

33. Shaikh Z, Pathak R. Revised Kuppuswamy and BG Prasad socioeconomic scales for 2016. Int J Community Med Public Health. 2017;4(4):997-999.

34. Rani D, Singh JK, Srivastava M, Verma P, Srivastava D, Singh S. Assessment of nutritional status of teenage adolescent girls in urban slum of Varanasi. Int J Cur Res Rev. 2018;10(20):6.

35. Meirelles C, Veiga G, Soares E. Nutritional status of vegetarian and omnivorous adolescent girls. Nutr Res. 2001;21(5):689-702. doi:10.1016/S0271-5317(01)00286-X

36. Khanam Z, Shankar H, Mishra C. Dietary diversity as an indicator of intra-household food accessibility: findings from a rural community of Varanasi district. Indian J Prev Soc Med. 2017;48(3-4):8.

37. Agrawal S. Frequency of food consumption and self-reported diabetes among adult men and women in India: a large scale nationally representative cross-sectional study. J Diabetes Metab. 2015;6 (1):474. doi:10.4172/2155-6156.1000474

38. Coates J, Swindale A, Bilinsky P. Household Food Insecurity Access Scale (HFIAS) for Measurement of Food Access: Indicator Guide. Washington, DC: Food and Nutrition Technical Assistance Project, Academy for Educational Development; 2007:34.

39. National Mental Health Working Group. Mental Health National Outcomes and Casemix Collection: Technical Specification of State and Territory Reporting Requirements for the Outcomes and Casemix Components of'Agreed Data', Version 1.50. Canberra:: Commonwealth Department of Health and Ageing; 2003.

40. Parveen S, Shafiq M. Mental health and coping among youth in kasmir: implications for psychological intervention. Delhi Psychiatry J. 2014;17(2).

41. Veit CT, Ware JE. The structure of psychological distress and wellbeing in general populations. J Consult Clin Psychol. 1983;51 (5):730-742. 
42. SOS Children's Villages Canada. Indian teenage girls are the world's most vulnerable to undernutrition. SOS CHILDREN'S VILLAGES CANADA. Available from: https://www.soschildrens villages.ca/girl-child-india-most-susceptible-malnutrition. Accessed August 03, 2020

43. Narayan J, John D, Ramadas N. Malnutrition in India: status and government initiatives. J Public Health Policy. 2019;40(1):126-141. doi:10.1057/s41271-018-0149-5

44. Singh N, Mishra CP. Nutritional status of adolescent girls of a slum community of Varanasi. Indian J Public Health. 2001;45 (4):128-134.

45. Manyanga T, El-Sayed H, Doku DT, Randall JR. The prevalence of underweight, overweight, obesity and associated risk factors among school-going adolescents in seven African countries. BMC Public Health. 2014;14(1):887. doi:10.1186/1471-2458-14-887

46. Deshmukh PR, Gupta SS, Bharambe MS, et al. Nutritional status of adolescents in rural Wardha. Indian J Pediatr. 2006;73(2):139-141. doi:10.1007/bf02820204

47. Dey I, Biswas R, Ray K, Bhattacherjee S, Chakraborty M, Pal P. Nutritional status of school going adolescents in a rural block of Darjeeling, West Bengal, India. Health. 2011;2(3):75-77.

48. Dong Y, Zou Z, Yang Z, et al. Prevalence of excess body weight and underweight among 26 Chinese ethnic minority children and adolescents in 2014: a cross-sectional observational study. BMC Public Health. 2018;18(1):562. doi:10.1186/s12889-018-5352-6

49. van Tuijl CJW, Madjdian DS, Bras H, Chalise B. Sociocultural and economic determinants of stunting and thinness among adolescent boys and girls in Nepal. J Biosoc Sci. 2020;1-26. doi:10.1017/ s0021932020000358

50. Grosso G, Mistretta A, Turconi G, Cena H, Roggi C, Galvano F. Nutrition knowledge and other determinants of food intake and lifestyle habits in children and young adolescents living in a rural area of Sicily, South Italy. Public Health Nutr. 2013;16(10):1827-1836. doi:10.1017/s1368980012003965

51. LÓPez PM, Anzid K, Cherkaoui M, Baali A, Lopez SR. Nutritional status of adolescents in the context of the moroccan nutritional transition: the role of parental education. J Biosoc Sci. 2012;44 (4):481-494. doi:10.1017/s0021932011000757

52. Pal A, Pari AK, Sinha A, Dhara PC. Prevalence of undernutrition and associated factors: a cross-sectional study among rural adolescents in West Bengal, India. Int J Pediatr Adolesc Med. 2017;4(1):9-18. doi:10.1016/j.ijpam.2016.08.009
53. Yu T, Chen C, Jin Z, et al. Association of number of siblings, birth order, and thinness in 3- to 12-year-old children: a population-based cross-sectional study in Shanghai, China. BMC Pediatr. 2020;20 (1):367. doi:10.1186/s12887-020-02261-Z

54. Demilew YM, Emiru AA. Under nutrition and associated factors among school adolescents in Dangila Town, Northwest Ethiopia: a cross sectional study. Afr Health Sci. 2018;18(3):756-766. doi:10.4314/ahs.v18i3.34

55. Belachew T, Hadley C, Lindstrom D, et al. Gender differences in food insecurity and morbidity among adolescents in southwest Ethiopia. Pediatrics. 2011;127(2):e398-e405. doi:10.1542/peds.2010-0944

56. Widome R, Neumark-Sztainer D, Hannan PJ, Haines J, Story M. Eating when there is not enough to eat: eating behaviors and perceptions of food among food-insecure youths. Am J Public Health. 2009;99(5):822-828. doi:10.2105/ajph.2008.139758

57. Loth K, van den Berg P, Eisenberg ME, Neumark-Sztainer D. Stressful life events and disordered eating behaviors: findings from project EAT. J Adolesc Health. 2008;43(5):514-516. doi:10.1016/j. jadohealth.2008.03.007

58. Bogale A, Shimelis A. Household level determinants of food insecurity in rural areas of Dire Dawa, Eastern Ethiopia. African J Food Agric Nutr Dev. 2009;9(9).

59. Piaseu N, Mitchell P. Household food insecurity among urban poor in Thailand. J Nurs Scholarsh. 2004;36(2):115-121. doi:10.1111/j.15475069.2004.04023.x

60. Kimani-Murage EW, Schofield L, Wekesah F, et al. Vulnerability to food insecurity in urban slums: experiences from Nairobi, Kenya. $J$ Urban Health. 2014;91(6):1098-1113. doi:10.1007/s11524-014-9894-3

61. O'Neil A, Quirk SE, Housden S, et al. Relationship between diet and mental health in children and adolescents: a systematic review. Am J Public Health. 2014;104(10):e31-e42. doi:10.2105/ajph.2014.302110

62. Khanna P, Chattu VK, Aeri BT. Nutritional aspects of depression in adolescents - a systematic review. Int J Prev Med. 2019;10:42. doi:10.4103/ijpvm.IJPVM_400_18

63. Wattick RA, Hagedorn RL, Olfert MD. Relationship between diet and mental health in a young adult appalachian college population. Nutrients. 2018;10(8):957. doi:10.3390/nu10080957

64. Tarasuk V, Mitchell A, McLaren L, McIntyre L. Chronic physical and mental health conditions among adults may increase vulnerability to household food insecurity. $J$ Nutr. 2013;143(11):1785-1793. doi:10.3945/jn.113.178483
Risk Management and Healthcare Policy

\section{Publish your work in this journal}

Risk Management and Healthcare Policy is an international, peerreviewed, open access journal focusing on all aspects of public health, policy, and preventative measures to promote good health and improve morbidity and mortality in the population. The journal welcomes submitted papers covering original research, basic science, clinical \& epidemiological studies, reviews and evaluations, guidelines, expert opinion and commentary, case reports and extended reports. The manuscript management system is completely online and includes a very quick and fair peer-review system, which is all easy to use. Visit http://www.dovepress.com/testimonials.php to read real quotes from published authors. 